Eechnical Note FOR INDUSTRY

\title{
KENNETH L. KELLY
}

U. S. DEPARTMENT OF COMMERCE

NATIONAL BUREAU OF STANDARDS 


\section{THE NATIONAL BUREAU OF STANDARDS}

\section{Functions and Activities}

The functions of the National Bureau of Standards are set forth in the Act of Congress, March 3, 1901, as amended by Congress in Public Law 619, 1950. These include the development and maintenance of the rational standards of measurement and the provision of means and methods for making measurements consistent with these standards; the determination of physical constants and properties of materials; the development of methods and instruments for testing materials; devices, and structures; advisory services to government agencies on scientific and technical problems; invention and development of devices to serve special needs of the Government; and the development of standard practices, codes, and specifications. The work includes basic and applied research, development, engineering, instrumentation, testing, evaluation, calibration services, and various consultation and information services. Research projects are also performed for other government agencies when the work relates to and supplements the basic program of the Bureau or when the Bureau's unique competence is required. The scope of activities is suggested by the listing of divisions and sections on the inside of the back cover.

\section{Publications}

The results of the Bureau's research are published either in the Bureau's own series of publications or in the journals of professional and scientific societies. The Bureau itself publishes three periodicals available from the Government Printing Office: The Journal of Research, published in four separate sections, presents complete scientific and technical papers; the Technical News Bulletin presents summary and preliminary reports on work in progress; and Basic Radio Propagation Predictions provides data for determining the best frequencies to use for radio communications throughout the world. There are also five series of nonperiodical publications: Monographs, Applied Mathematics Series, Handbooks, Miscellaneous Publications, and Technical Notes.

A complete listing of the Bureau's publications can be found in National Bureau of Standards Circular 460, Publications of the National Bureau of Standards, 1901 to June 1947 (\$1.25), and the Supplement to National Bureau of Standards Circular 460, July 1947 to June 1957 (\$1.50), and Miscellaneous Publication 240, July 1957 to June 1960 (Includes Titles of Papers Published in Outside Journals 1950 to 1959)(\$2.25); available from the Superintendent of Documents, Government Printing Office, Washington 25, D. C. 


\title{
NATIONAL BUREAU OF STANDARDS Eechnical Note
}

152

NOVEMBER 1962

\section{COORDINATED COLOR IDENTIFICATIONS FOR INDUSTRY}

\author{
Kenneth L. Kelly
}

\begin{abstract}
NBS Technical Notes are designed to supplement the Bureau's regular publications program. They provide a means for making available scientific data that are of transient or limited interest. Technical Notes may be listed or referred to in the open literature.
\end{abstract}




\section{Contents}

1. Introduction........................... 1

2. Discussion............................. 2

3. Summary............................... 6

4. Bibliography............................. 7 
When a color is to be identified; the preciseness required of the identification is the first consideration. Usually this is determined by a trial-and-error method which can be both costly and time-consuming. For some uses, a color name consisting of a hue name or a hue name and modifier is sufficient while for others, a notation of the color in a color-order system will suffice. Where maximum precision is required, the color should be measured instrumentally and the results expressed numerically. This paper describes the coordinated series of five levels of fineness of color identification developed by ISCC Subcommittee for Problem 23, the Expression of Historical Color Usage, and is based on the ISCC-NBS method of designating colors. It lists the methods for changing from one level to another and gives examples of the use of each level.

\section{Introduction}

There has long been a need in industry and science for a coordinated series of different levels of fineness of color designation. Such a series was developed by the Inter-Society Color Council Subcommittee for Problem 23, the Expression of Historical Color, Usage, that is, color trends. This series was mentioned in the report 1 of that subcommittee in connection with the necessary statistical aqalysis, and again in the paper, Some Problems of Color Identification 17, given before the Fal1 Conference of the Building Research Institute incidental to the description of other color-order systems. This paper will bring into sharper focus the five levels of fineness of color designation inherent in this series.

This series is based on the method of color designation developed at the National Bureau of Standards with the cooperation of the InterSociety Color Council as an answer to the problem of deşribing the colors of drugs and medicines, in the National Formulary 1 and in the United States Pharmacopoeia ${ }^{2}$. In it the psychological color solid $30,41 /$ was divided into 319 blocks, to each of which was assigned a simple easily understood color name consisting of a hue name, such as red or green, and one or more modifiers to produce designations such as light yellowish brown or pale pink. Since each block is tridimensional, that is, since the color range included in it varies in hue (red, yellow, green), lightness (1ight, dark), and saturation (vivid, strong, weak), it was necessary to tailor the size and shape of each color-name block so that the color range included would represent the range of color associated by the average person with that color designation. The description of these 319 cofor-name blocks was included in the paper, Method of Designating Color $\underline{14}$, published in 1939. 
In 1946, this ISCC-NBS (Inter-Society Color Council - National Bureau of Standards) method was revised to take account of suggested changes in the color-name boundaries especially with relation to the textile industry. Some hue names were deleted and one added and the number of color names was reduced to 267 . The color-name charts defining the boundaries of these 267 color-name blocks are contained in National Bureau of Standards Circular 553, the ISCC-NBS Method of Designating Colors and a Dictionary of Color Names 19/. The instructions for determining these color names were extended to apply not only to drugs and medicines but rather to any powder, solid, liquid, or microscopic structure without restriction. The modifier weak was replaced with grayish due to the undesirable connotation of the former in such descriptions as a weak red brick.

\section{Discussion}

There are many applications in industry and science for which this division of the color solid into 267 parts would be sufficient, but perhaps the most important application of the ISCC-NBS method of designating colors is in serving as the basic structure by which the five levels of fineness of color designation are coordinated. It goes further and contains the first three levels.

For instance, there are nineteen modifiers for the hue range green not including those for yellowish green or bluish green. All of these from greenish white to vivid green can be described as greens; that is, these nineteen color names can be combined or "rolled up" into one hue name. Likewise the ten color names describing yellowish greens can all be described by the hue name yellowish green, and the nine color names describing bluish green colors can be described by the hue name bluish green. Also since yellowish green and bluish green are variations of green they can all be described by the generic hue name green. This then is why the ISCC Subcommittee for Problem 23 called this coordinated series of color-identification systems the color roll-up system, for all the 38 color names describing various greens can first be rolled up into yellowish green, green, or bluish green; and then these three, into the generic hue name green.

The five levels of fineness of color identification each embrace the whole psychological color solid and are related through the ISCC-NBS method of designating colors. In the first level, the color solid is divided into thirteen parts, ten described by a generic hue name, and three neutrals, white, gray and black. These generic hue names are pink, red, orange, brown, yellow, olive, green, blue, violet and purple. In the second leve1, the color solid is divided into 29 parts, that is ten of the original 13 parts are further divided and assigned intermediate hue names. These intermediate hue names are yellowish pink, reddish orange, reddish brown, orange yellow, yellowish brown, olive brown, greenish yellow, yellow green, olive green, yellowish green, bluish green, greenish blue, purplish blue, reddish purple, purplish red and purplish pink. In the third level, each part of the color solid described by a generic or intermediate hue name is subdivided and to each such sub- 
division is assigned that hue name and the appropriate modifier descriptive of its lightness and saturation as shown in the table of modifiers in Circular 553 on page 3. These modifiers include vivid, brilliant, strong, deep, very deep, very light, light, moderate, dark, very dark, very pale, pale, grayish, dark grayish, and blackish. The part of the color solid described by the color name gray, is subdivided into three parts to each of which is assigned a modifier descriptive of its 1ightness, 1ight, medium or dark. This is the ISCC-NBS method of designating colors and consists of the 267 color-name blocks in Circular 553.

Leve1 four of our coordingted series is illustrated by the Munsel1 Book of Color $9,15,18,22,25,26,31 /$. There are about 1000 color samples in this book which have been prepared with great care to exemplify equally spaced scales of hue, lightness, and saturation, on which the boundaries of the ISCC-NBS color-name blocks are based. That is, the Munse11 color system is a true color-appearance system and as such lends itself to interpolation and extrapolation among its color samples. So if the desired color is not found among the 1000 samples, its designation may be indicated by specifying its hue to the nearest half hue step out of the 100 hue steps in the Munse11 hue circuit, to the nearest one tenth value step (lightness) of the ten value steps between white (Munsel1 notation 10/) and black (Munsell notation $0 /$ ), and to the nearest third chroma step (saturation). The chroma notation of the most saturated color sample in the Munse11 Book of Color is /16. Thus the effective number of hues has been increased to 200 by interpolation alone from the 40 constant-hue charts of the Munsell Book of Color, a five-fold increase; the number of values has been increased from 10 to 100 , and the number of chromas has been multiplied by 6 . It may be said that by interpolation alone, the effective number of Munsell color samples has been increased by a factor of approximately $5 \times 10 \times 6=300$ (or to a total of about 300,000 colors). Also since the boundaries of the ISCC-NBS color-name blocks are specified in terms of the Munsell system, it is easy to determine the ISCC-NBS color name equivalent to any Munsel1 notation throughout the color solid.

In level five, the color is measured on a colorimeter or spectrophotometer and the results expressed numerically $3,13,32 /$. The greatest accuracy required in the identification of a color can be realized in this leve1. The numerical results obtained from a colorimeter or spectrophotometer are usually expressed in chromaticity coordinates ( $x, y$ or $a, b$ ) and daylight reflectance $\left(Y\right.$ or $R_{d}$ ) and are reliable to two decimal places and sometimes to three. It is hoped that in the not too distant future, through the development of new spectrophotometers coupled with highspeed electronic computers, values of chromaticity coordinates and daylight reflectances obtained spectrophotometrically can be given correct to three decimal places and possibly to four.

Now let us consider an example whose color can be appropriately described on each of the five levels of fineness of color identification. It is possible that the manufacturer of snow-shovel handles who wanted red, green or blue handles for his product to satisfy his customer's desire for color variety, would be perfectly happy to have nearly any 
red, green or blue and would not be too fussy about the tolerances within which the handles matched his selected colors. He would thus be using level one. If, however, the green was found to be too yellowish or bluish, he could refine his tolerances by advancing to level two of our coordinated series by stating that he wanted a green handle and not a yellowish green or bluish green one. Suppose now as our manufacturer's knowledge of color increases, and his customers become more sophisticated, he may find through a color survey that he should have specified a vivid red instead of the less expensive uncontrolled red which he had been using. He may have found that vivid red has more eye appeal and further that it contrasts better with snow and green grass. He has thus advanced from level two to level three, that is, to the ISCC-NBS method of designating colors.

If, however, our industrialist's product is one which must "go with" another colored item, he may well find that this division of the whole color solid into 267 color-name blocks does not give him the color selection which he requires. He must then advance to level four and specify his color in terms of the Munsell color system or an equivalent color-order system. Now let us progress to another industrialist, one who produces refrigerators. He may well sublet the contract for the manufacture of the refrigerator bodies and doors to one manufacturer and that of the plastic cooling-compartment doors to another. Here the tolerances are much more stringent and even an interpolated Munsell notation may not suffice. He must then resort to a color measuring instrument, a colorimeter or a spectrophotometer. Both of these instruments have advantages and disadvantages and the industrialist must know both or his inspection costs may become too high. Our industrialist has now advanced to level five of our coordinated series of color identification systems.

From the descriptions of levels four and five, it can be seen that there is a considerable variation of fineness of designation for a color in each of these levels. In level four, for instance, the Munsell Book of Color contains about 1000 color samples, but this figure can be multiplied by approximately 300 through the use of interpolation alone, while other color-order systems which can also be used in this level contain from 943 to 7056 color samples. In level five, the variation in fineness of color designation is accomplished by increasing the number of decimal places used in the numerical notation. Remember that the number of color designations possible with two decimal places (for each of three coordinates) will be increased by a factor of 1000 with three decimal places and by a factor of 1,000,000 with four decimal places. This flexibility is most useful and fortunate in these levels since they will be used more and more in industry and science in the specification of colors and color differences.

In 1943 there was published at the National Bureau of Standards a
paper 18 luding graphs illustrating the chromaticity coordinates and
tables listing the daylight reflectances of the 405 color samples in the
20-hue edition of the Munsell Book of Color. Also in 1943 the 2 ptiral
Society of America published the results of an extensive study of the 
Munsel1 system which attempted through graphs and tables to define an idea1 Munse11 color system. To distinguish Munsel1 notations determined through the comparison of a color with the color scales of the Munsel1 Book of Color, called Munsel1 book notations, from notations in the ideal Munse11 color system, the latter are called Munsell renotations. From either of these sets of graphs, it is possible to convert chromaticity coordinates and daylight reflectances to Munsel1 book notations or renotations. The latter are usyally used. Lately through elegant programs for highspeed computers , it has been possible to determine in a matter of seconds the Munsell renotation of a color from its chromaticity coordinates and daylight reflectance.

Now let us summarize the levels of fineness in reverse order. For maximum accuracy, a color should be measured instrumentally and the results expressed numerically or in terms of a Munsell renotation (level five). If this accuracy is not required, a carefully interpolated Munsel1 book notation may suffice (level four). If one wants a quick understandable color designation such as that of a moist soil sample before its color changes due to drying, a description in terms of the ISCC-NBS color names can be recorded (level three). If one is interested in the color of a thin section of a sample under the microscope where the thickness of the section is not easily controlled, the hue name of the color in question is usually sufficient (leve1 two). Leve1 one is useful when a quick approximate designation of a color is sufficient or when color changes or trends are being plotted and where more than thirteen lines on a graph would be confusing.

It has long been the hope of the National Bureau of Standards and the Inter-Society Color Council that someday color charts could be added to the color-names dictionary with a characteristic color sample illustrating each of the color-name blocks. These most characteristic colors were considered to be those representing the centers of the blocks and thus are called centroid colors. The ISCC-NBS centroid colors were defined at the 6 National Bureau of Standards by specifications determined mathematically in terms of Munse11 renotations, some of the centroids being outside the color range of available pigments. Through financial support from the Inter-Society Color Council the prototype centroid colors meeting the tolerances prescribed by this Bureau were produced by Davidson and Hemmendinger of Easton, Pa., for 214 of the 267 color-name blocks. Mass produced constant-hue name centroidcolor charts are in preparation and will be available through the Standard Materials Program of the National Bureau of Standards, Washington 25, D.C. at about $\$ 2.00$ per complete set.

Through the publication of the Munsel1 notations of part or all of the color samples of such well known and much $2 y$ sg color-order systems

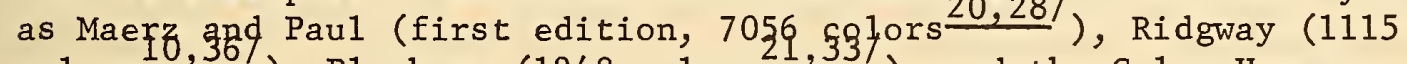
colors $(\underline{10})$, Plochere $\left(1248 \operatorname{col}_{\mathrm{gr}}\left\{\frac{21,33 /}{2,38 /}\right)\right.$, and the Color Harmony Manual (third edition, 943 colors $, 12,38 / 2)$, these color-order systems can be used in place of the Munsell Book of Color in level four. Each of these color-order systems has as many as, or more color samples than, the Munsel1 Book of Color and these samples are arranged systematically 
throughout the whole color solid. There are other collections of color samples, smaller than the Munsell Book of Color, whose Munsell notations have been published; theseginclude the ninth edition of the Standard Color Card ( 216 colors 34,397 , produced by the Textile Color Card Association of the United States (now the Color Association of the United States), the Horticultural Colourghart (800 colors 4 , 27), the 256 colors shown in the Nickerson Color Fan , the 88 colors used by the American Association of Textile Chemists and 7 Golourists 37 , Federal specification TT-C-595 (first edition, 187 colors - ) $6 /$ the 17 colors for molded urea and 12 / colors for polystyrene plastics-, th 33 yock colors ( 115 colors, $1951\left(\frac{24}{)}\right)$, and the 196 for soil colors (1954 $\frac{23}{}$ ). These smaller collections besides their specific applications, can be used in level three of our coordinated series of color identification systems. In addition to the color samples in the Munsell Book of Color, those in the Color Harmony Manual (third edition) and in the ninth edition of the Standard Color Card have been measured spectrophotometrically and the corresponding chromaticity coordinates, daylight reflectances, and Munsell renotations have been published.

To assist in coordinating the color identifications derived from these many collections of color samples, there are listed in the third part of NBS Circular 553, the color names dictionary, all of the color names used in these color-order systems with their equivalent ISCC-NBS color designations. In the second part of NBS Circular 553, all of these color names are listed, each under its equivalent ISCC-NBS color name. Opposite each of these color names in part two, is listed the numerical or letter designation used in each collection to identify the color sample.

\section{Summary}

It was the stated purpose of this paper to describe the method, developed by ISCC Subcommittee for Problem 23, of coordinating the five levels of fineness of color designation. The application of this method to the color problems of industry and science is increasing. The change is slow but sure and the dye man in the shop is finding that the advertising man is beginning to understand what he, the dye man, is talking about and vice versa. As the use of this method spreads, men from different industries will find that they have finally a common language for the designation of colors and color differences. One commercial firm is applying this coordinated series to the study of color selection and color trends involving all products that offer the intermediate customer a choice of colors on the manufacturing level as well as the ultimate consumer on the retail level. Through the use of this method it is possible by statistical treatment to correlate marketing data on products whose colors are described in any one of the five levels of fineness of color designation. 


\section{Bibliography}

1 American Pharmaceutical Association, The National Formulary (revised every five years).

2 American Society for Testing Materials, Committee D-1, Method of specifying color by the Munsell system, ASTM Designation: D1535-58T, issued 1958 .

3 American Standards Association, Standard Methods of Measuring and Specifying Color, Z58.7.1-1951, Z58.7.2-1951, and Z58.7.3-1951, is sued 1951.

4 The British Colour Council in collaboration with the Royal Horticultural Society (London), Horticultural colour chart, 1938 and 1940. Copyright Robert F. Wilson. Also issued as the Wilson Colour chart.

5 Colors for molded urea plastics, Commercial Standard CS147-47, U.S. Department of Commerce, $12 / 15 / 47$.

6 Colors for polystyrene plastics, Commercial Standard CS156-49, U.S. Department of Commerce, $1 / 1 / 49$.

7 Federa1 Specification TT-C-595, Colors; (for) Ready-Mixed Paints. Procurable from the Superintendent of Documents, U.S. Government Printing Office, Washington 25, D.C., \$4.50. Dated January 12, 1950 and issued in 1951.

8 Granville, W. C., Munsel1 renotations of Color Harmony Manual chips (third edition) from spectrophotometric measurements. Unpublished. Available from Container Corporation of America.

9 Granville, W.C., Nickerson, D., and Foss, C.E., Trichromatic specifications for intermediate and special colors of the Munsell system, J. Opt. Soc. Am. 33, 376-385 (1943).

10 Hamly, D.H., The Ridgway color standards with a Munsell notation key, J. Opt. Soc. Am. 39, 592-599 (1949).

11 Inter-Society Color Counci1, Interim Report of the ISCC Subcommittee on Problem 23, Expression of historical color usage, Nov. 20, 1960.

12 Jacobson, E., Color Harmony Manua1, Container Corporation of America, Chicago, I1linois, 1948, third edition.

13 Judd, D.B., Color in Business, Science and Industry, John Wiley \& Sons, Inc., New York, 1952.

14 Judd, D.B. and Kelly, K.L., Method of designating colors, J. Research NBS 23, 355-385 (1939) RP1239. 
15 Judd, D.B. and Wyszecki, Glinter, Extension of the Munsel1 renotation system to very dark colors, J. Opt. Soc. Am. 46, 281-284 (Apri1 1956).

16 Kelly, K.L., Central notations for the revised ISCC-NBS color-name blocks, J. Research NBS 61, 427-431 (Nov. 1958) RP2911.

17 Kelly, K.L., Some problems of color itentification, J. Am. Institute of Architects 37, 80-82 (Mar. 1962).

18 Kelly, K.L., Gibson, K.S., and Nickerson, D., Tristimulus specification of the Munse11 Book of Color from spectrophotometric measurements, J. Research NBS 31, 55 (1943) RP1549; a1so J. Opt. Soc. Am. 33, 355-376 (July 1943).

19 Kelly, K.L. and Judd, D.B., The ISCC-NBS method of designating colors and a dictionary of color names, NBS Circular 553, Nov. 1, 1955.

20 Maerz, A. and Paul, M. Rea, A Dictionary of Color, First Edition, McGraw-Hi11 Book Company, Inc., 1930.

21 Middleton, W.E. Knowles, The Plochere color system; A descriptive analysis, Canadian J. Research, F.27, 1-21 (1949); N.R.C. No. 1856 ; also J. Opt. Soc. Am. 39, 633A (1949).

22 Munse11 Color Company, Munse11 Book of Color, 1960 edition, Munse11 Color Company, Inc., 2441 North Calvert Street, Baltimore 18, Md.

23 Munse11 Color Company, Munsel1 soil color charts, special form for use of Soil Scientists, Geologists, and Archaeologists, 1954. Munsell Color Company, Baltimore 18, Md.

24 National Research Council, Rock-color chart, prepared by the RockColor Chart Committee (sponsored by 5 geological organizations), Washington, D.C., 1951.

25 Newha11, S.M., Preliminary report of the OSA subcommittee on the spacing of the Munsell colors, J. Opt. Soc. Am. 30, 617-645 (1940).

26 Newha11, S.M., Nickerson, D., and Judd, D.B., Final report of the OSA subcommittee on the spacing of the Munsel1 Colors, J. Opt. Soc. Am. 33, 385-418 (1943).

27 Nickerson, Dorothy, Horticultural Colour Chart names with Munse11 key, J. Opt. Soc. Am. 47, 619-621 (July 1957).

28 Nickerson, Dorothy, Interrelation of color specifications, Paper Trade J. 125, 153 (1947). 
29 Nickerson, Dorothy, Modern color science is the background for a new and useful color chart for horticulture, Proc. 11 th Annual Am. Horticultural Congress and Annual Meeting Am. Horticultural Council, p.3 - 11, Oct. 1956.

30 Nickerson, Dorothy, and Newha11, S.M., A psychological color solid, J. Opt. Soc. Am. 33, 419-422 (July 1943).

31 Nickerson, D., Tomaszewski, J.J., and Boyd, T.F., Colorimetric specifications of Munsel1 repaints, J. Opt. Soc. Am. 43, 163-171 (1953).

32 Optical Society of America, Committee on Colorimetry, The Science of Color, Thomas Y. Crowe11 Co., New York, 1953.

33 Plochere, G. and Plochere, G., Plochere Color System, A guide to color and color harmony, Fox Printing Co., Los Angeles, California, 1948.

34 Reimann, G., Judd, D.B., and Keegan, H.J., Spectrophotometric and colorimetric determination of the colors of the TCCA standard color cards. J. Research NBS 36, 209-247 (1946) RP1700; also J. Opt. Soc. Am. 36, 128-159 (Mar. 19,46).

35 Rheinboldt, W.C. and Menard, J.P., Mechanized conversion of colorimetric data to Munsel1 renotations, J. Opt. Soc. Am. 50, 802-807 (Aug. 1960).

36 Ridgway, Robert, Color standards and color nomenclature, Washington, D.C., 1912.

37 The Society of Dyers and Colourists, Colour Index, Bradford, Yorkshire, England, January 1924, Supplement January 1928.

38 Taylor, Helen D., Knoche, Lucille, and Granville, Walter C., Descriptive Color Names Dictionary, Container Corporation of America, Chicago, Illinois, 1950.

39 Textile Color Card Association of the United States, Inc., Standard Color Card of America, 9th Edition, Color Association of the United States, 200 Madison Avenue, New York 16, N.Y., 1941.

40 United States Pharmacopoeial Convention, The Pharmacopoeia of the United States of America (revised every five years).

41 Webster's Third New Internationa1 Dictionary, unabridged, G. and C. Merriam Co., Springfield 2, Mass., 1961. 

NATIONAL BUREAU OF STANDARDS

A. V. Astin, Director

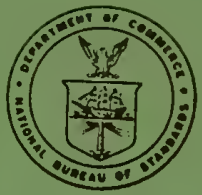

\section{THE NATIONAL BUREAU OF STANDARDS}

The scope of activities of the National Bureau of Standards at its major laboratories in Washington, D.C., and Boulder, Colorado, is suggested in the following listing of the divisions and sections engaged in technical work. In general, each section carries aut specialized research, development, and engineering in the field indicated by its title. A brief description of the activities, and of the resultant publications, appears on the inside of the front cover.

\section{WASHINGTON, D. C.}

Electricity. Resistance and Reactance. Electrochemistry. Electrical Instruments. Magnetic Measurements Dielectrics. High Voltage.

Metrology. Photometry and Colorimetry. Refractometry. Photographic Research. Length. Engineering Metrology. Mass and Scale. Volumetry and Densimetry.

Heat. Temperature Physics. Heat Measurements. Cryogenic Physics. Equation of State. Statistical Physics. Radiation Physics. X-ray. Radioactivity. Radiation Theory. High Energy Radiation. Radiological Equipment. Nucleonic lnstrumentation. Neutron Physics.

Analytical and Inorganic Chemistry. Pure Substances. Spectrochemistry. Solution Chemistry. Standard Reference Materials. Applied Analytical Research. Crystal Chemistry.

Mechanics. Sound. Pressure and Vacuum. Fluid Mechanics. Engineering Mechanics. Rheology. Combustion Controls.

Polymers. Macromolecules: Synthesis and Structure. Polymer Chemistry. Polymer Physics. Polymer Characterization. Polymer Evaluation and Testing. Applied Polymer Standards and Research. Dental Research.

Metallurgy. Engineering Metallurgy. Microscopy and Diffraction. Metal Reactions. Metal Physics. Electrolysis and Metal Deposition.

Inorganic Solids. Engineering Ceramics. Glass. Solid State Chemistry. Crystal Growth. Physical Properties. Crystallography.

Building Research. Structural Engineering. Fire Research. Mechanical Systems. Organic Building Materials. Codes and Safety Standards. Heat Transfer. Inorganic Building Materials. Metallic Building Materials.

Applied Mathematics. Numerical Analysis. Computation. Statistical Engineering. Mathematical Physics. Operations Research.

Data Processing Systems, Components and Techniques. Computer Technology. Measurements Automation. Engineering Applications. Systems Analysis.

Atomic Physics. Spectroscopy. Infrared Spectroscopy. Far Ultraviolet Physics. Solid State Physics. Electron Physics. Atomic Physics. Plasma Spectroscopy.

Instrumentation. Engineering Electronics. Electron Devices. Electronic Instrumentation. Mechanical Instruments. Basic Instrumentation.

Physical Chemistry. Thermochemistry. Surface Chemistry. Organic Chemistry. Molecular Spectroscopy. Elementary Processes. Mass Spectrometry. Photochemistry and Radiation Chemistry.

office of Weights and Measures.

\section{BOULDER, COLO.}

Cryogenic Engineering Laboratory. Cryogenic Equipment. Cryogenic Processes. Properties of Materials. Cryogenic Technical Services.

\section{CENTRAI, RADIO PROPAGATION LABORATORY}

Ionosphere Research and Propagation. Low Frequency and Very Low Frequency Research. Ionosphere Research. Prediction Services. Sun-Earth Relationships. Field Engineering. Radio Warning Services. Vertical Soundings Research.

Radio Propagation Engineering. Data Reduction Instrumentation. Radio Noise. Tropospheric Measurements. Tropospheric Analysis. Propagation-Terrain Effects. Radio-Meteorology. Lower Atmosphere Physics.

Radio Systems. Applied Electromagnetic Theory. High Frequency and Very High Frequency Research. Frequency Utilization. Modulation Research. Antenna Research. Radiodetermination.

Upper Atmosphere and Space Physics. Upper Atmosphere and Plasma Physics. High Latitude Ionosphere Physics. lonosphere and Exosphere Scatter. Airglow and Aurora. Ionospheric Radio Astronomy.

\section{RADIO STANDARDS LABORATORY}

Radio Physics. Radio Broadcast Service. Radio and Microwave Materials. Atomic Frequency and Time-Interval Standards. Radio Plasma. Millimeter-Wave Research.

Circuit Standards. High Frequency Electrical Standards. High Frequency Calibration Services. High Frequency lmpedance Standards. Microwave Calibration Services. Microwave Circuit Standards. Low Frequency Calibration Services. 
$+1 \mathrm{BS}>$

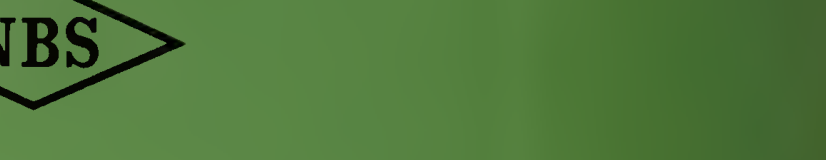

NBS

NBS

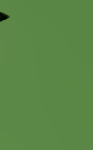

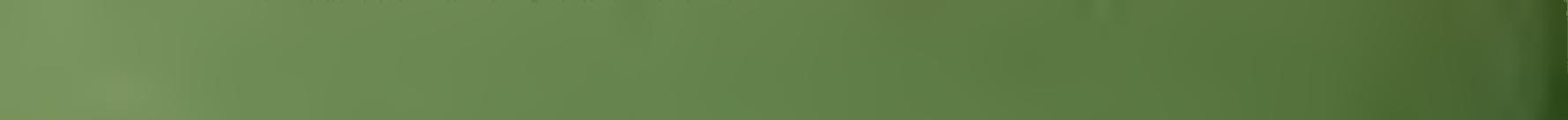

$+$

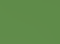

